\title{
Analisa dan Perancangan Aplikasi Peminjaman dan Pengembalian LCD Proyektor di Universitas Potensi Utama Medan Menggunakan QR Code
}

\author{
Analysis and Design of Lending and Returning LCD Projector Applications at the Universitas \\ Potensi Utama Medan using QR Code \\ Sofyan Rahmad \\ Jurusan Sistem Informasi Universitas Potensi Utama \\ Universitas Potensi Utama, K.L. Yos Sudarso KM 6,5 No. 3A Tj. Mulia-Medan \\ Email : sofyanrahmad99@gmail.com
}

\begin{abstract}
ABSTRAK
Unversitas Potensi Utama sudah memiliki aplikasi peminjaman projector berbasis desktop yang digunakan sebagai pelayanan dalam peminjaman LCD proyektor oleh dosen yang berada di bagian teknisi untuk membantu dosen dalam proses belajar mengajar. Pada saat ini aplikasi yang sudah dibangun kurang efesien atau efektif untuk penggunanya karena para dosen yang meminjam LCD proyektor sering salah dalam melakukan penginputan data kedalam aplikasi tersebut dan aplikasi tersebut belum mendukung dalam memblok atau melarang dosen ketika yang bersangkutan belum mengembalikan LCD Proyektor pada hari yang sama. Dari uraian masalah diatas, maka peneliti ingin membantu dalam meng-Update aplikasi peminjaman LCD proyektor pada bagian teknisi Universitas Potensi Utama dengan tambahan fitur berupa QR Code untuk meminimalisir kesalahan penggunanya. Didalam aplikasi yang akan dibangun menggunakan $Q R$ Code dengan cara ditempelkan kepada kamera web (webcam) dengan database SQL Server 2008 dan aplikasi Visual Studio 2010 sehingga pelayanan peminjaman LCD proyektor lebih efesien dan efektif untuk di gunakan di Universitas Potensi Utama Medan
\end{abstract}

Kata Kunci: Univeritas Potensi Utama, QR Code ,Aplikasi, Proyektor,

\section{ABSTRACT}

Unversitas Potensi Utama already has a desktop-based projector loan application which is used as a service in lending LCD projectors by lecturers who are in the technician section to assist lecturers in the teaching and learning process. At this time the application that has been built is less efficient or effective for its users because lecturers who borrow LCD projectors are often wrong in inputting data into the application and the application has not supported blocking or prohibiting lecturers when they have not returned the LCD projector on the same day. From the description of the problem above, the researcher wants to help in updating the LCD projector loan application at the Main Potential University technician with additional features in the form of a $Q R$ Code to minimize user errors. In the application to be built using a QR Code by attaching it to a web camera (webcam) with the SQL Server 2008 database and the Visual Studio 2010 application so that the LCD projector lending service is more efficient and effective for use at the Universitas Potensi Utama Medan

Keywords: University Potensi Utama, QR Code, Application, Projector

\section{PENDAHULUAN}

Pada saat ini sedang berkembangnya teknologi berbasis $Q R$ Code (Quick Response) yang digunakan untuk mempermudah dalam penggunaan teknologi salah satunya dalam keamanan sistem ataupun dalam pembuatan suatau tanda khusus dalam satu objek yang ingin dibuat. $Q R$ 
Code adalah image berupa matriks dua dimensi yang memiliki kemampuan untuk menyimpan data di dalamnya. QR Code merupakan evolusi dari kode batang (barcode). Barcode merupakan sebuah simbol penandaan objek nyata yang terbuat dari pola batang-batang berwarna hitam dan putih agar mudah untuk dikenali oleh komputer. (Situmorang, Pandia Gunawan, dkk, 2017)

Unversitas Potensi Utama sudah memiliki aplikasi peminjaman projector berbasis desktop yang digunakan sebagai pelayanan dalam peminjaman $L C D$ proyektor oleh dosen yang berada di bagian teknisi untuk membantu dosen dalam proses belajar mengajar. Aplikasi yang sudah dibangun kurang efesien atau efektif untuk penggunanya karena para dosen yang meminjam $L C D$ proyektor sering salah dalam melakukan penginputan data kedalam aplikasi tersebut dan aplikasi tersebut belum mendukung dalam memblok atau melarang dosen ketika yang bersangkutan belum mengembalikan $L C D$ Proyektor pada hari yang sama. Dari uraian masalah diatas, maka peneliti ingin membantu dalam meng-Update aplikasi peminjaman $L C D$ proyektor pada bagian teknisi dengan tambahan fitur berupa $Q R$ Code untuk meminimalisir kesalahan penggunanya. Didalam aplikasi yang akan dibangun menggunakan $Q R$ Code dengan cara ditempelkan kepada kamera web (web came).

Dalam penyusunan Penelitian ini, penulis banyak terinspirasi dan mereferensi dari jurnal penelitian-penelitian sebelumnya yang berkaitan dengan latar belakang masalah pada Penelitian ini. Adapun jurnal penelitian yang berhubungan dengan Penelitian ini antara lain yaitu jurnal penelitian Jeri Ariska, 2015, yang berjudul "Rancang Bangun Sistem Informasi Manajemen Aset Sekolah Menggunakan Teknik Labelling GR Code (Studi Kasus: MAN 2 Model Pekanbaru)" menyatakan bahwa dengan adanya Sistem Informasi Manajemen Aset Sekolah ini nantinya dapat mempermudah petugas dalam administrasi data aset secara detail, pencarian data aset, pelaporan aset dan monitoring aset secara keseluruhan. Adapun menurut jurnal Darmanta, 2017 yang berjudul "Penerapan teknoligi barcode pada pengelolaan data pembayaran sumbangan pembinaan pendidikan(SPP)" menyatakan bahwa dengan adanya teknologi barcode dapat mempermudah pencaarian data dan memepermudah pihak sekolah dalam proses pelayanan.

QR-Code merupakan teknik yang mengubah data tertulis menjadi kode-kode 2-dimensi yang tercetak ke dalam suatu media yang lebih ringkas.QR-Code adalah barcode 2-dimensi yang diperkenalkan pertama kali oleh perusahan Jepang Denso-Wave pada tahun 1994. Barcode ini pertama kali digunakan untuk pendataan invertaris produksi suku cadang kendaraan dan sekarang sudah digunakan dalam berbagai bidang. QR adalah singkatan dari Quick Response karena ditujukan untuk diterjemahkan isinya dengan cepat. QR-Code merupakan pengembangan dari barcode satu dimensi, QR-Code salah satu tipe dari barcode yang dapat dibaca menggunakan kamera handphone. QR-Code mampu menyimpan semua jenis data, seperti data angka/numerik, alphanumerik, biner, kanji/kana.Selain itu QR-Code memiliki tampilan yang lebih kecil daripada barcode.Hal ini dikarenakan QR-Code mampu menampung data secara horizontal dan vertikal, jadi secara otomatis ukuran dari tampilannya gambar QR-Code bisa hanya seperspuluh dari ukuran sebuah barcode.Tidak hanya itu QR-Code juga tahan terhadap kerusakan, sebab QR-Code mampu memperbaiki kesalahan sampai dengan 30\% tergantung dengan ukuran atau versinya.Oleh karena itu, walaupun sebagian simbol QR-Code kotor ataupun rusak, data tetap dapat disimpan dan dibaca. Tiga tanda berbentuk persegi di tiga sudut memiliki fungsi agar simbol dapat dibaca dengan hasil yang sama dari sudut manapun. (Eka Ardhianto, dkk, 2016)

Dari uraian masalah diatas, maka penulis ingin membantu dalam meng-Update aplikasi peminjaman $L C D$ proyektor pada bagian teknisi Universitas Potensi Utama dengan tambahan fitur berupa $Q R$ Code untuk meminimalisir kesalahan penggunanya.

\section{METOLOGI PENELITIAN}

Metode-metode yang peneliti gunakan dalam merancang, menulis, dan mengembangkan penelitian ini terdiri dari beberapa bagian yang saling terkait dan saling melengkapi, yakni :

1. Metode Analisis dan Perancangan

Metode analisis dan perancangan yang digunakan dalam penelitian ini adalah Unified Modeling Language (UML) yang mencakup flowchart, use case diagram, dan rancangan layar. 
2. Studi Kepustakaan

Yaitu suatu penelitian pribadi yang peneliti lakukan guna mengumpulkan landasan teori sebaik-baiknya dan sebenar-benarnya dengan cara membaca, mempelajari, dan mencari buku-buku bacaan, berbagai makalah dan topik pembahasan ilmiah maupun umum, dan literatur-literatur yang berhubungan dengan topik yang peneliti hadapi untuk dikembangkan. Berbagai sumber peneliti cari, baik yang bersifat badaniah (hadir langsung, mengunjungi perpustakaan, toko buku, meminjam buku-buku milik teman dan dosen, koleksi pribadi peneliti) maupun pencarian informasi yang bersifat maya (melalui internet, forum-forum diskusi, artikel pendukung riset penelitian peneliti, beragam e-book pendukung, dan lain-lain).

Prosedur Perancangan

Berisi tatacara dan langkah-langkah yang diperlukan untuk mencapai tujuan perancangan yang dilakukan. Dapat dilihat pada Gambar di bawah ini

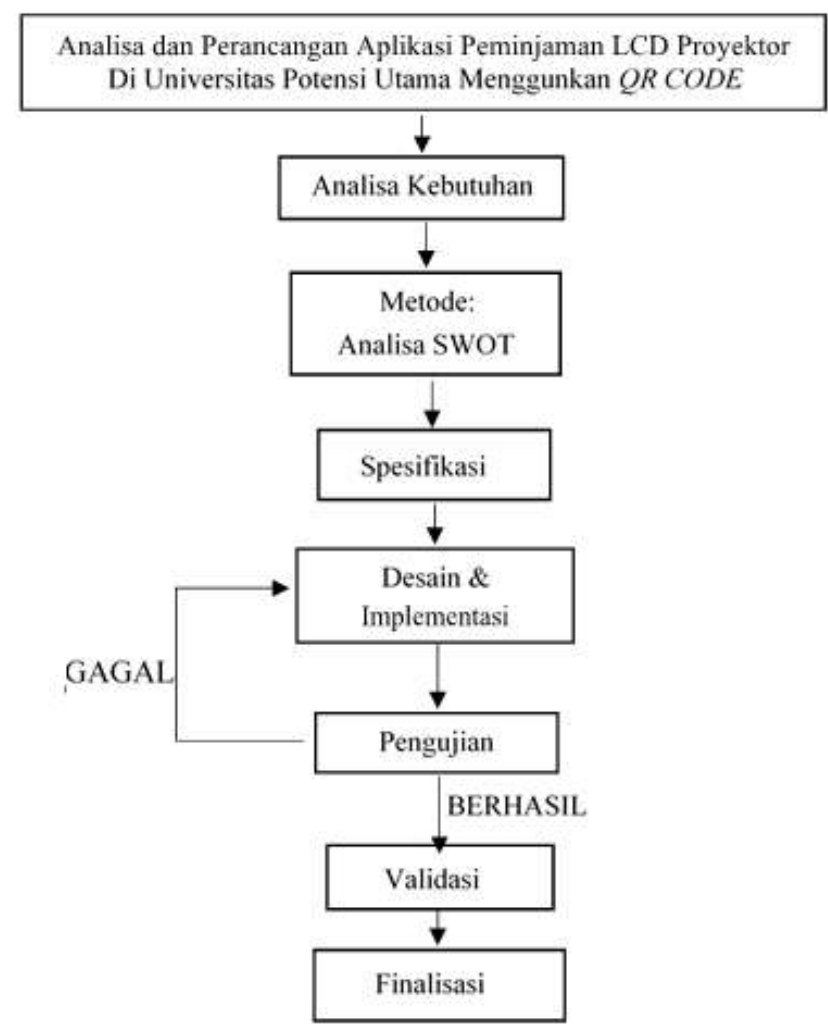

Gambar 1. Perancangan Sistem

Beberapa kebutuhan yang harus dipenuhi demi terciptanya suatu program aplikasi verifikasi sertifikat, maka harus tersedianya beberapa komponen yang dibutuhkan, diantaranya adalah :

1. Analisa kebutuhan

A. Kebutuhan antarmuka

Adapun kebutuhan antarmuka yang dimaksud yaitu :

1. Aplikasi harus mampu memproses setiap proyektor yang di scan dan memberikan data yang valid.

2. Aplikasi harus mempunyai tampilan-tampilan yang familiar bagi pemakai.

3. Aplikasi harus mampu menyimpan, memperbarui, menghapus data ke dalam storage database.

4. Ada proses dalam aplikasi yang mampu memperbarui semua data yang disimpan dalam storage database.

B. Kebutuhan fungsional

Adapun kebutuhan fungsional yang dimaksud yaitu : 
1. Mengelola semua data yang dimasukan oleh admin dan user dengan benar.

2. Menghasilkan output berupa laporan peminjaman dan pengembalian proyektor tiap semesternya

3. Mengefesiensi dan efektifkan peminjamann dan pengembalian proyektor untuk memperbaruhi system yang sudah ada

\section{Metode SWOT}

Metode yang digunakan dalam pembuatan aplikasi adalah metode SWOT. Dikarenakan sistem yang akan dibangun adalah sistem sudah ada dan akan dianalisa dengan SWOT apakah sistem tersebut layak untuk diperbaharuin atau meng-update dari sistem yang sudah ada

3. Spesifikasi dan Desain

Aplikasi peminjaman dan pengembalian proyektor menggunakan laptop dan webcam dengan spesifikasi sebagai berikut :

1. Processor Laptop : Intel DualQore, $1.90 \mathrm{Ghz}$

2. RAM :4 GB

3. Kamera WebCam

4. Operating System : Microsoft Windows 7 dan Windows 10

5. Aplikasi : Visual Studio 2015

6. Crystal report 2010

7. NET. Framework 4.0

8. SQL Server 2008 R2

4. Implementasi Sistem

Setelah semua peralatan yang dibutuhkan telah disiapkan secara keseluruhan maka implementasi dari aplikasi peminjaman dan pengembalian proyektor menggunakan $Q R$ Code sebagai berikut: Dosen menginput ID Dosen dari NIDN dosen ke textbox ID Dosen, dan system menampilkan data dosen seperti nama dosen dan jabatan. Berikutnya dosen dibantu admin men-Scan kode $Q R$ Code yang sudah ada di tas proyektor. Ketika dosen sudah selesai proses belajar mengajar, dosen mengembalikan proyektor dengan men-Scan kembali lagi kode QR Code nomor proyektor yang dipinjam. Apabila dosen tidak mengembalikan proyektor pada hari yang sama maka system akan memblok sementara dosen tersebut tidak bias meminjam proyektor selama seminggu atau 7 hari setelah har peminjaman.

5. Validasi

Pengaplikasian setiap hasil yang ada, baik dalam bentuk program maupun kenyataan yang terjadi pada alat tersebut, dipelihara dalam bentuk dokumentasi, guna memberi keterangan terhadap permasalahan agar diketahui apakah aplikasi yang digunakan dapat dikembangkan atau tidak.

6. Finalisasi

Hasil dari yang sudah di validasi akan dilengkapkan dengan menyusun kelengkapan dari program yang belum sempurna dengan melengkapi dokumen- dokumen pendukung dari pembuatan program yang akan dibangun.

\section{HASIL DAN PEMBAHASAN}

\subsection{Pembahasan}

Berdasarkan uraian masalah diatas di temukan beberapa masalah sehingga penulis menguraikan masalah tersebut dibagian hasil dan pembahasan sebagai berikut:

\subsubsection{Analisa Internal Organisasi}

Dari hasil observasi pada Aplikasi peminjaman dan pengembalian proyektor di bagian teknisi, maka ditemukan mengenai beberapa kekuatan dan kelemahan internal yang dimiliki saat ini yaitu:

1. Kekuatan Sistem

a. Kelengkapan Data 
Data yang ada di aplikasi sudah terjaga dikarenakan pemyimpanan data sudah menggunakan database terkomputerisasi

b. Efesiensi penggunaan

Penggunaan aplikasi tersebut mudah digunakan karena berbasis dekstop

2. Kelemahan Sistem

a. Sistem Blok

Sistem belum dilengkapi untuk memblok dosen pada peminjaman berikutnya ketika dosen tidak mengembalikan proyektor pada hari yang sama

b. Kinerja SDM

Sering terjadi kesalahan dalam penginputan nama dosen ataupun nomor proyektor sehingga menyulitkan petugas untuk mengidentifikasi proyektor yang belum dikembalikan

\subsubsection{Eksternal Organisasi}

Ekternal organisasi meliputi peluang dan ancaman, seperti berikut ini:

1. Peluang atau Kesempatan

Peluang merupakan salah satu hal yang dapat diraih dan dicapai sedangkan kesempatan merupakan sesuatu yang bisa dimanfaatkan Aplikasi peminjaman dan pengembalian proyektor untuk pengembangan selanjutnya. Adapun peluang- peluang yang dapat diraih oleh perpustakaan diantaranya adalah:

a. Menerapkan sytem automatic banned

Penerapan Iupdate aplication untuk membuat blok bagi dosen yang tidak mengembalikan proyektor pada hari yang sama untuk peminjaman berikutnya selama 7 hari terhitung sejak peminjaman.

b. Penambahan fitur QR Code

Penambahan fitur QR code pada nomor proyektor berguna untuk meminimalisir kesalahan dalam penginputan nomor proyektor.

2. Kendala atau Ancaman

Adapun ancaman atau kendala yang dapat menggangu adalah:

a. Data peminjam tidak efektif

Apabila nomor proyektor yang diketik tidak dengan benar dapat membuat petugas sulit dalam mengidentikasi proyektor.

b. Keamanan

Keamanan validasi data dosen merupakan salah satu kendala, sehingga perlu diperhatikan bagaimana menginput data dosen berdasarkan data yang benar yang akan melakukan peminjaman

\subsubsection{Rating nilai dan perhitungan}

Berdasarkan pemetaan SWOT yang telah dijelaskan sebelumnya, maka tahapan berikutnya adalah penyajian data dan mensistemasi pokok-pokok informasi untuk dapat melihat hubungan antara data-data yang diperoleh. Berdasarkan data tersebut dapat dilakukan pemetaan dalam bentuk matrik SWOT. Dalam penelitian ini sebelum dipetakan kedalam matrik SWOT untuk tahap selanjutnya memperhitungkan tabel IFAS (Internal Factor Analysis Summary) dan EFAS (External Factor Analysis Summary) tabel ini digunakan untuk pemetaan lingkungan internal yang dalam hal ini adalah kekuatan dan kelemahan dan merupakan salah satu faktor untuk mengembangkan Aplikasi peminjaman dan pengembalian proyektor bagian teknisi di Universitas Potensi Utama.

Untuk nilai atau peringkat yang terdapat dalam tabel di dapat dari respon pihak dosen saat melakukan kuesioner dan pengamatan langsung ke lapangan. Adapun rentang peringkat faktor strategis pada IFAS dan EFAS seperti pada tabel 1 dibawah ini: 
Tabel 1. Rating Nilai

\begin{tabular}{|l|l|}
\hline \multicolumn{1}{|c|}{ Rentang Nilai } & Peringkat \\
\hline $1-2$ & Sangat Rendah \\
\hline $2-3$ & Rendah \\
\hline $3-3.5$ & Sedang \\
\hline $3.5-4$ & Tinggi \\
\hline
\end{tabular}

Dari rentang nilai peringkat faktor strategis diatas digunakan untuk mencari nilai IFAS dan EFAS. Kriteria IFAS dan EFAS kita dapatkan dari faktor strategis. Berikut merupakan display data tentang lingkungan internal.

Tabel 2 Faktor Strategis Internal

\begin{tabular}{|c|c|c|c|c|c|}
\hline \multicolumn{2}{|c|}{ Faktor Strategis Internal } & \multicolumn{5}{|c|}{ Peringkat Faktor Strategis } \\
\hline \multicolumn{2}{|c|}{ Kekuatan (S) } & 4 & 3 & 2 & 1 \\
\hline 1 & Kelengkapan Data & & $\sqrt{ }$ & & \\
\hline 2 & Efesiensi penggunaan & $\sqrt{ }$ & & & \\
\hline \multicolumn{2}{|c|}{ Nilai Rata-Rata Faktor Strategis } & \multicolumn{5}{|c|}{3.25} \\
\hline \multicolumn{2}{|c|}{ Kelemahan (W) } & 4 & 3 & 2 & 1 \\
\hline 1 & Update content/informasi & & $\sqrt{ }$ & & \\
\hline 2 & Kinerja SDM & & & $\sqrt{ }$ & \\
\hline \multicolumn{2}{|c|}{ Nilai Rata-Rata Faktor Strategis } & \multicolumn{5}{|c|}{} \\
\hline
\end{tabular}

Masing - masing factor strategis internal merupakan faktor-faktor strategis yang dapat mempengaruhi organisasi. Setiap variabel memiliki nilai yang berbeda. Hasil dari responden berikut menunjukan bahwa faktor-faktor lingkungan internal yakni pada faktor kekuatan memiliki nilai 3.25 yang berarti bahwa faktor-faktor pada bagian kekuatan memilki peringkat sedang. Untuk pengembangan selanjutnya perlu ditingkatkan kembali kekuatan. Untuk faktor internal kelemahan mendapatkan nilai 2.5 .

Menarik kesimpulan dari atas dapat maka aplikasi yang telah berjalan yang ada dibagian teknisi Universitas Potensi Utama dapat di update karena memiliki rating rendah yang berguna untuk mengefesiensi penggunaannya.

\subsection{Hasil}

Berdasarkan pembahasan maka di temukannya hasil dengan sebuah perancangan desain program aplikasi peminjaman LCD proyektor dengan menggunakan $Q R$ Code sebagai berikut:

\subsubsection{Perancangan program usecase diagram}

Perilaku beserta tugas-tugas dari tiap-tiap elemen maupun aktor yang terlibat dalam sistem yang akan dirancang, akan digambarkan dalam diagram use case yang bertujuan untuk memberikan gambaran secara umum tentang sistem yang akan dirancang. 


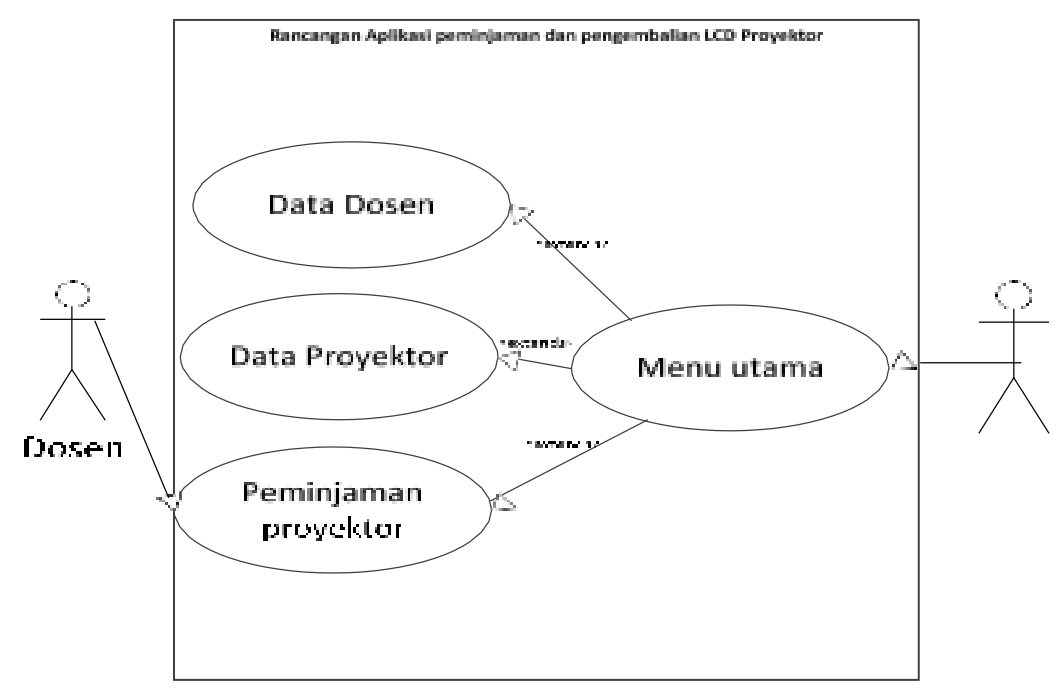

Gambar 2. Use Case Diagram

3.2.2 Tampilan hasil dari program Aplikasi

Berikut ini adalah tampilan hasil dari perancangan Aplikasi Peminjaman dan Pengembalian LCD Proyektor pada Universitas Potensi Utama Medan sebagai berikut:

A. Form Menu Utama

Form menu utama berfungsi sebagai tampilan awal penggunakan sebelum memilih formform yang ada di aplikasi. Adapun tampilannya dapat diliat pada gambar sebagai berikut:

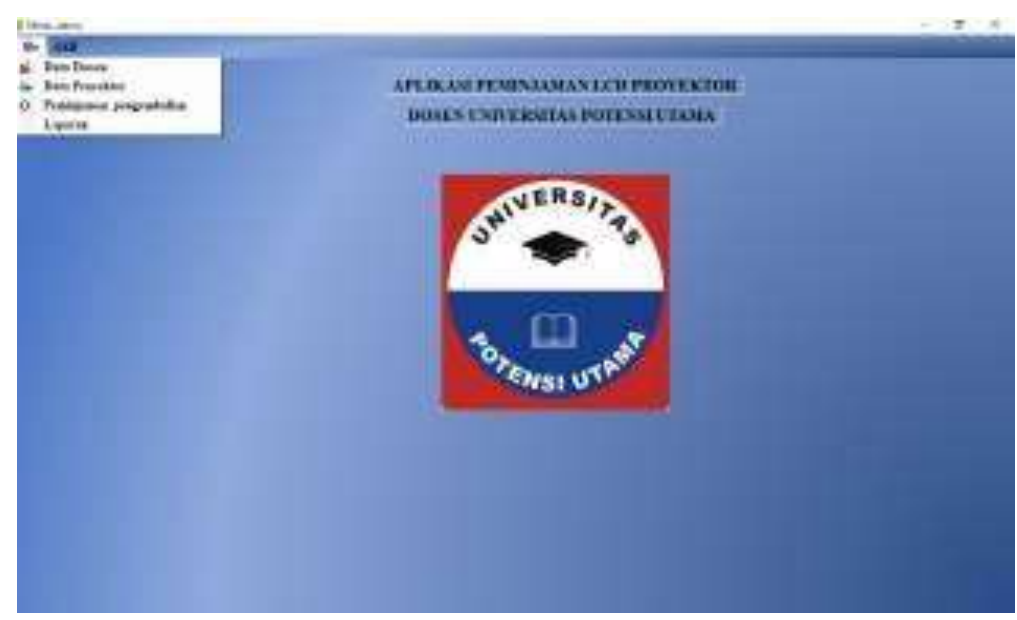

Gambar 3. Tampilan Menu Utama

B. Tampilan input data dosen

Form input data dosen berfungsi untuk mengubah atau memasukan data dosen sebagai peminjaman proyektor. Adapun tampilannya diliahat pada gambar berikut: 


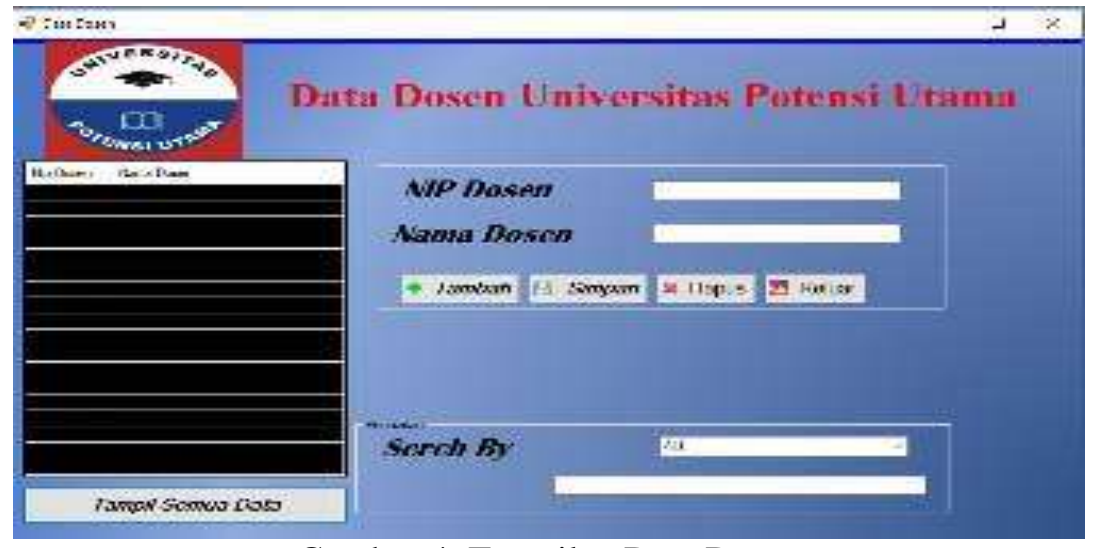

Gambar 4. Tampilan Data Dosen

C. Tampilan Buat QR code untuk proyektor

Form tersebut untuk pembuatan QR Code LCD proyektor. Adapun tampilannya diliahat pada gambar berikut:

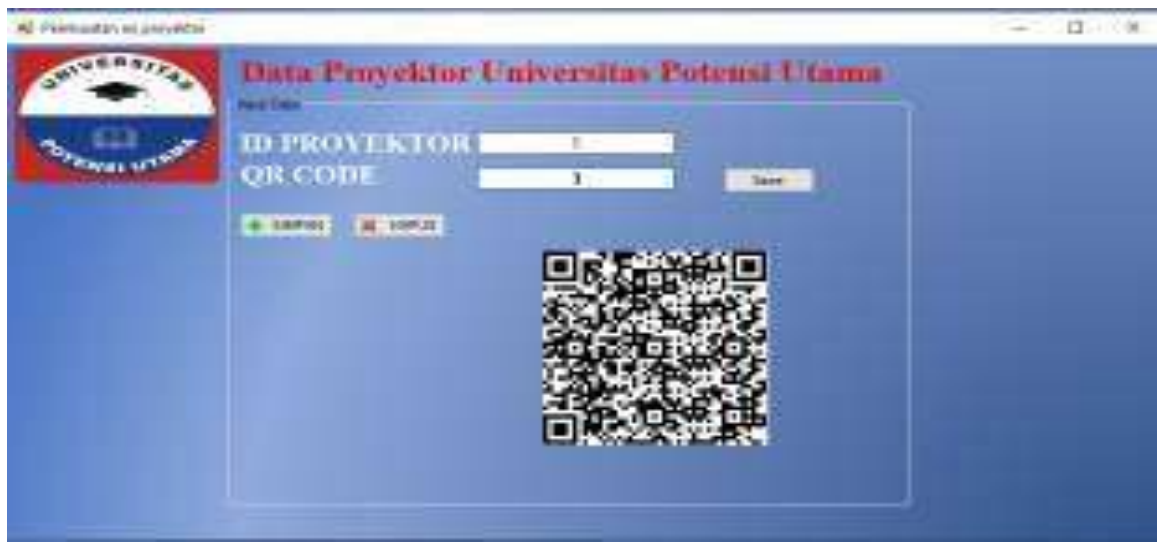

Gambar 5. Tampilan Pembuatan $Q R$ Code untuk proyektor

D. Tampilan peminjaman dan pengembalian lcd Proyektor

Form tersebut peminjaman dan pengembalian lcd proyektor. Adapun tampilan pada gambar berikut:

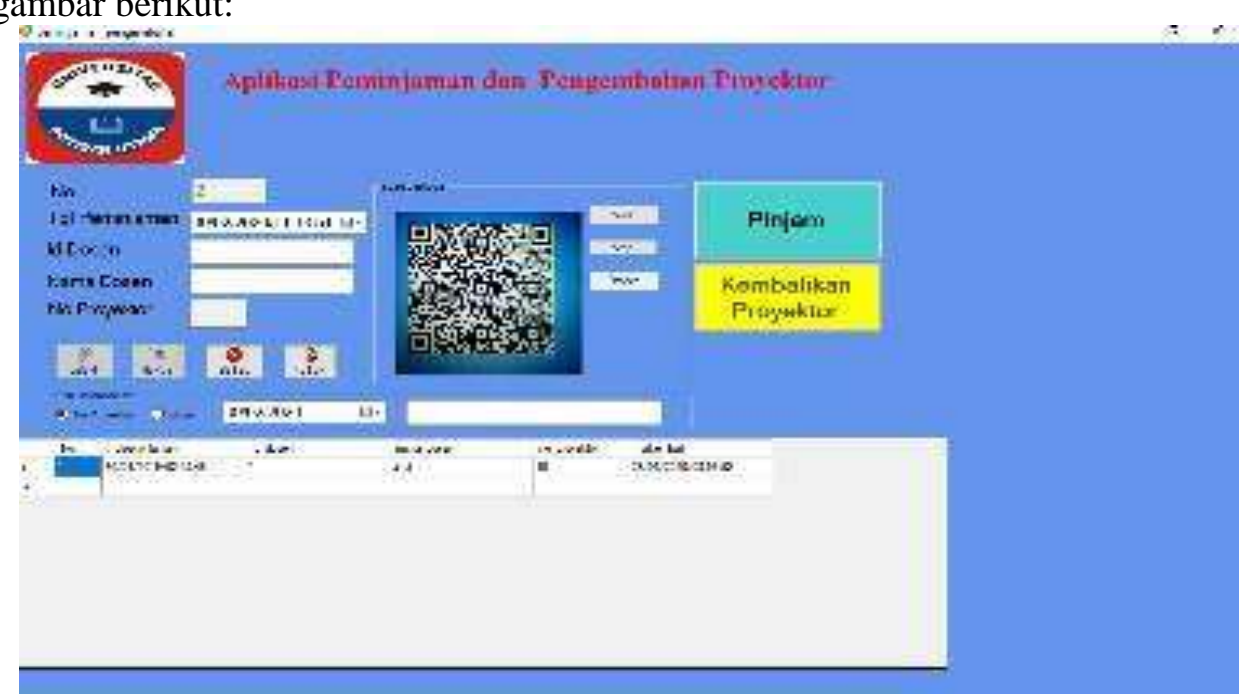

Gambar 6. Tampilan Pembuatan $Q R$ Code untuk proyektor 


\subsubsection{Uji Coba Hasil}

Uji coba hasil terhadap sistem bertujuan untuk memastikan bahwa sistem sudah berada pada kondisi siap pakai. Instrumen yang digunakan untuk melakukan pengujian ini yaitu dengan menggunakan :

A. Satu unit laptop dengan spesifikasi sebagai berikut :
1. Processor Intel Core I3
2. Memory $4 \mathrm{~Gb}$
3. Hardisk $500 \mathrm{G}$

B. Perangkat Lunak dengan spesifikasi sebagai berikut :

1. Visual Basic 2015

C. Pengujian Sistem :

1. Tampilan sistem

2. Informasi yang dihasilkan oleh sistem

3. Penyajian laporan

\subsubsection{Skenario Pengujian}

Melakukan pengujian terhadap hasil dan membandingkan dengan konsep penyelesaian masalah yang telah dirancang pada bab sebelumnya, apakah hasilnya sesuai dengan apa yang penulis inginkan.

Tabel 3. Skenario Pengujian

\begin{tabular}{|c|c|c|c|c|}
\hline No. & $\begin{array}{l}\text { Skenario } \\
\text { Penguiian }\end{array}$ & Test case & Hasil yang diharapkan & $\begin{array}{c}\text { Hasil } \\
\text { penguiian }\end{array}$ \\
\hline 1 & Menu Utama & $\begin{array}{l}\text { Button file } \\
\text { Button data dosen } \\
\text { Button data } \\
\text { proyektor } \\
\text { Button data } \\
\text { peminjam }\end{array}$ & $\begin{array}{l}\text { Sistem akan menampilkan } \\
\text { beberapa tombol dengan } \\
\text { tujuan berbeda. Form tersebut } \\
\text { adalah bentuk awal tampilan } \\
\text { system yang akan digunakan }\end{array}$ & Valid \\
\hline 2 & $\begin{array}{l}\text { Form Data } \\
\text { Proyektor }\end{array}$ & $\begin{array}{l}\text { Button Simpan } \\
\text { Button hapus } \\
\text { Button simpan } \\
\text { gambat }\end{array}$ & $\begin{array}{l}\text { Button simpan, berfungsi } \\
\text { untuk menyimpan data } \\
\text { Proyektor yang telah } \\
\text { ditambahkan. } \\
\text { Button hapus berfungsi } \\
\text { mengahapus data di database } \\
\text { Button simpan gambar } \\
\text { berfungsi sebagai simpan } \\
\text { gambar } Q R \text { Code di file untuk } \\
\text { dicetak }\end{array}$ & Valid \\
\hline 6 & $\begin{array}{l}\text { Form Data } \\
\text { Dosen }\end{array}$ & $\begin{array}{l}\text { Button Tambah } \\
\text { Button Edit } \\
\text { Button Hapus } \\
\text { Button Edit }\end{array}$ & $\begin{array}{l}\text { Button tambah, sistem akan } \\
\text { melakukan penambahan data } \\
\text { dosen button edit, untuk } \\
\text { melakukan perubahan data } \\
\text { dosen, button hapus, } \\
\text { digunakan untuk menghapus } \\
\text { data, dan button edit kriteria } \\
\text { untuk memasukkan data } \\
\text { kriteria pada setiap nama } \\
\text { dosen. }\end{array}$ & Valid \\
\hline 6 & $\begin{array}{c}\text { Form } \\
\text { Peminjaman }\end{array}$ & $\begin{array}{l}\text { Button pinjam } \\
\text { Button Kembali } \\
\text { Button Hapus } \\
\text { Button Edit } \\
\text { Button scan }\end{array}$ & $\begin{array}{l}\text { Button Pinjam, sistem akan } \\
\text { melakukan penambahan data } \\
\text { peminjamn, button edit, untuk } \\
\text { melakukan perubahan data } \\
\text { dosen, button hapus, }\end{array}$ & Valid \\
\hline
\end{tabular}




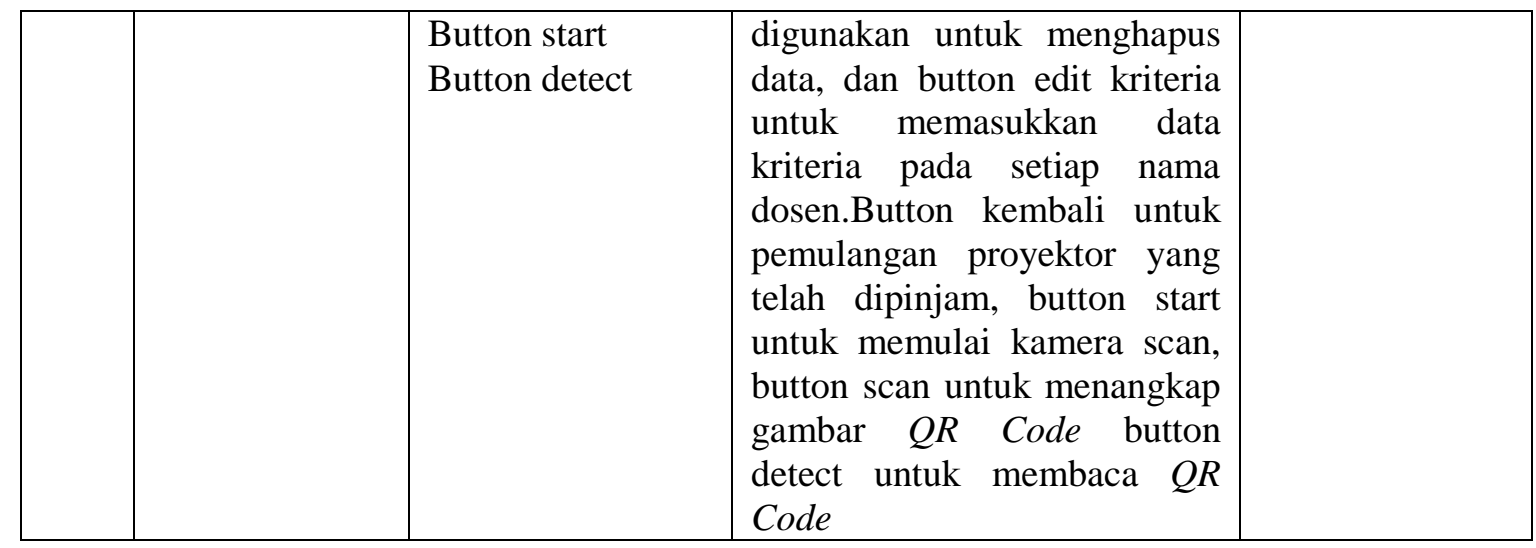

\subsubsection{Hasil Pengujian}

Setelah melakukan uji coba terhadap sistem, maka dapat disimpulkan hasil yang didapatkan yaitu :

a. Sistem memiliki performance yang relatif stabil.

b. Sistem hanya membutuhkan \pm 3.5 detik untuk melakukan start-up.

c. Sistem telah menghasilkan informasi yang valid.

d. Antarmuka yang sederhana dapat mempermudahpengguna dalam mempelajari sistem ini.

\subsubsection{Kelebihan dan Kekurangan Sistem}

Setiap sistem memiliki kelebihan dan kekurangan, berikut ini adalah kelebihan dan kekurangan sistem yang telah dibuat.

1. Kelebihan Sistem:

Kelebihan sistem ini diantaranya yaitu:

a. Sistem sudah menggunakan $Q R$ Code scanner untuk mendeteksi proyektor yang akan dipinjam untuk kegiatann proses belajar mengajar.

b. Performance sistem relatif stabil.

c. Sistem mampu menghasilkan informasi yang sesuai dengan yang diharapkan.

d. Sistem sangat cepat mengolah data untuk menghasilkan berbagai informasi yang dibutuhkan pengguna.

2. Kekurangan Sistem

Adapun kekurangan sistem yang telah dibuat diantaranya yaitu :

a. Sistem masih belum Stabil jika menggunakan camera scanner dengan picxel rendah

b. Penggunaan sistem masih membutuhkan waktu yang cukup lama dikarenakan pakar pengguna sistem masih harus mempelajari sistem terlebih dahulu sebelum menggunakan sistem.

c. Sistem tidak memiliki backup data secara otomatis agar terhindar dari kemungkinan terjadinya kehilangan data penting yang disebabkan oleh kerusakan pada perangkat keras.

\section{KESIMPULAN}

Berdasarkan penelitian yang telah dilakukan selama membuat aplikasi peminjaman lcd proyektor menggunakan $Q R$ Code di Universitas Potensi Utama, maka dapat ditarik beberapa kesimpulan sebagai berikut:

1. Sistem yang dibuat untuk memudahkan dosen dalam meminjam LCD proyektor dibagian teknisi universitas Potensi Utama

2. Memberikan kemudahan pada pihak teknisi untuk mendata LCD proyektor yang digunakan oleh pihak dosen dan Memberikan data yang akurat kepada pihak teknisi untuk melayani dosen dalam peinjaman. 
3. Bahasa pemrograman yang digunakan untuk membuat aplikasi yaitu Visual Basic 2015 dan database yang digunakan yaitu SQL Server 2008 R2, Menganalisa system yang sebelumnya menggunakan metode SWOT

\section{SARAN}

Sebagai aplikasi yang tidak dikerjakan dengan tim, penulis menyadari bahwa aplikasi ini memiliki banyak kekurangan, saran untuk pengembangan aplikasi pada waktu mendatang adalah:

1. Sebaiknya sistem ini dikembangkan agar mampu memberika pelayanan yang lebih maksimal terhadap dosen yang meminjam

2. Selalu mem-backup data agar terhindar dari kemungkinan terjadinya kehilangan data penting yang disebabkan oleh kerusakan pada perangkat keras.

3. Sebaiknya agar system yang dibuat agar diperguankan sebaik-baiknya di bagian teknisi Universitas Potensi Utama Medan

4. Mengembangkan sistem pendukung keputusan ini dengan sistem client server.

\section{UCAPAN TERIMA KASIH}

Dengan ini maka penulis mengucapkan terima kasih yang sebesar-besarnya kepada Universitas Potensi Utama yang telah membantu penulis dalam menyelesaikan penelitian ini.

\section{DAFTAR PUSTAKA}

[1] Rahmawati, A., \& Rahman, A. (2011). Sistem Pengamanan Keaslian Ijasah Menggunakan QR-Code dan Algoritma Base64. Program Studi Sistem Informasi, Universitas Ahmad Dahlan, 1(2).

[2] Nurcahyono, F. (2017). Pembangunan aplikasi penjualan dan stok barang Pada toko nuansa elektronik pacitan. Speed-Sentra Penelitian Engineering dan Edukasi, 4(3).

[3] Ismail, I. (2011). Sertifikat sebagai Alat Bukti Hak Atas Tanah dalam Proses Peradilan. Kanun Jurnal Ilmu Hukum, 13(1), 23-34.

[4] Rahayu, Y. D., Ramadijanti, N., \& Setiowati, Y. (2010). Pembuatan Aplikasi Pembacaan Quick Response Code Menggunakan Perangkat Mobile Berbasis J2ME Untuk Identifikasi Suatu Barang. eepis final project.

[5] Ulfah, M. (2005). ANALISIS DAN IMPLEMENTASI SISTEM KEAMANAN DATA DENGAN MENGGUNAKAN METODE ENKRIPSI ALGORITMA RC5 (Doctoral dissertation, Universitas Komputer Indonesia).

[6] Mustakim, M., \& Krisnawati, K. (2014). Analisis Dan Perancangan Sistem Informasi Akuntansi Laporan Keuangan Pada Pusat Perusahaan Distributor Air Mineral Mq Jernih Yogyakarta. Data Manajemen dan Teknologi Informasi (DASI), 15(3), 26.

[7] Kurniawan, H. (2017, November). PERANCANGAN SISTEM APLIKASI UJIAN SELEKSI PEGAWAI BERBASIS ONLINE. In Seminar Nasional Informatika (SNIf) (Vol. 1, No. 1, pp. 312-317).

[8] Syahputri, N. (2017, November). SISTEM INFORMASI PENGELOLAAN PERWALIAN MAHASISWA BERBASIS WEB. In Seminar Nasional Informatika (SNIf) (Vol. 1, No. 1, pp. 448-456). 